\title{
Psychiatrists' Perception of Continuing Medical Education
}

Gopala S Poduri

\begin{abstract}
Background: The number of continuing medical education (CME) programmes is becoming increasingly more in recent times and there were no formal reported studies among psychiatrists in India.
\end{abstract}

Objective: To find out psychiatrist's general opinion about CME.

Materials and methods: Data were collected from a representative sample of psychiatrists in active practice about CMEs attended in the last 5 years using a proforma through email and representative contacts. The general impression about CME and faculty was collected apart from personal data. The opinion regarding $\mathrm{CME}$ credit hours for renewal of medical council of India $(\mathrm{MCl})$ registration was obtained by a question. Data were analysed using descriptive statistics and Cronbach's alpha was computed for reliability, validity and to know the data adequacy of the test to perform

Results: In all responses from 202 participants were analysed. Majority of responders were below 40 years (64\%). More than half were in the profession for less than 10 years. Two-fifth conducted CME and nearly a third were office-bearers mostly in city associations. Sixty-six percent attended because of topic while $34 \%$ for faculty and $21 \%$ for $\mathrm{MCl}$ renewal. Thirty-six percent were either partly or fully sponsored by pharmaceutical companies. While $58 \%$ participants and $74 \%$ faculty found CME favorably, on the unfavourable side the figure were $21 \%$ and $51 \%$ respectively. More than half $(55 \%)$ were against the need of $\mathrm{CME}$ for renewal of registration.

Conclusion: An unconditional positive regard may be good for psychiatric therapy but the same cannot be said of CME.

Keywords: Acceptance, Continuing medical education, Psychiatrists opinion.

How to cite this article: Poduri GS. Psychiatrists' Perception of Continuing Medical Education (CME). Ind J Priv Psychiatry 2018;12(2):46-49.

\section{Source of support: Nil}

Conflict of interest: None

\section{INTRODUCTION}

Continuing medical education (CME)-continuing professional development (CPD) in general, consists of educational activities which serve to maintain, develop, or increase

\section{Consultant}

Yashoda Super-speciality Hospital, Malakpet, Hyderabad, Telangana, India

Corresponding Author: Gopala S Poduri, Consultant, Yashoda Super-speciality Hospital, Malakpet, Hyderabad, Telangana, India, e-mail: gopalasarmapoduri@hotmail.com the knowledge, skills, and professional performance and relationships that a physician uses to provide services for patients, the public, or the profession as per Accreditation Council of Continuing Medical Education (ACCME). ${ }^{1}$ Government of India decided in 1985 to utilize the services of Indian Physicians settled in United States in CME and patient care in India, which was extended in 1993 to involve Indian doctors from United Kingdom and Canada and named $\mathrm{MCI}$ as the nodal agency for collaborating these schemes and CME. A cell was set up in the council office in December, 1985 for that purposes. In November 1999, the Central Government, Ministry of Health and Family Welfare had also extended its approval to hold the CME programmes without participation of non-resident Indian (NRI) faculty from USA/UK/Canada. ${ }^{2}$ Further, this participation was also driven by regulation and policy, with member organizations, colleges, or Government requiring evidence of a continuing ability to practice medicine-a process termed recertification which was initiated in India in April 2002. ${ }^{3}$ The first CME in psychiatry was started in 1983 by Dr L. P. Shah in Mumbai on the 35th anniversary of the Indian Psychiatric Society. The first mid-term CME was held in $1990{ }^{4}$ Since then there has been a quantum jump in CMEs which is aided and abetted by more and more state medical councils opting for credit hours for medical registration renewal.

The lack of a structured and integrated medical education curriculum, non-uniformity in rules for mandatory CME credits, differences in standards of CME accreditation across the states, confusion on the recognition status of online CME and funding policies are some of the hindrances faced in structuring policies and executing CME programmes for the healthcare profession. ${ }^{5}$

Continuing medical education (CME) can be viewed from various perspectives of organisers, state medical councils, pharmaceutical companies, participants, event managers, and hospitality industry. Everybody benefits from CMEs in one way or other. With psychiatric societies conducting annual, mid-term CMEs, followed by zone, state and city branches, Medical colleges, psychiatry departments following suite, psychiatrists have plenty of CMEs to choose from. However, not all the CMEs are qualified for credit hours for medical registration renewal.

When an event is held, much planning is done before hand and stocktaking after. Extensive work precedes the actual occurrence of CME. With streamlining of the procedures almost to perfection and organizations-event 
managers, ready to take the burden albeit for a hefty price, the organizers work is cut to order and perfection in conducting the CME. From the participant's angle, CME involves expenses such as registration, travel, accommodation at times responsible for loss of income during the period, loosing patients due to absence of doctor, etc. So, alternatives such as online services, cost-effectiveness, medical renewal and credit hours, are some of the issues / concerns apart from the speaker, topic, and venue. Stocktaking is needed to find out if the objective with which it was held was achieved. The evaluation process should be in place to ensure that the practical needs of participants were fulfilled. The CME has been evaluated in various parameters in most of the countries and where some found it beneficial while others did not.

There have been no documented studies on CME in Indian psychiatry in the literature. Hence, a survey was undertaken to find out psychiatrists' view on various aspects of CME.

\section{MATERIALS AND METHODS}

The sample was from all over the country. A simple random sample from the list of psychiatrists was chosen and taken-up for survey. The survey was done through an email communication. When there was no response, reminders by personal phone/mail/SMS/WhatsApp was done. If still there was no response, mails were sent to other persons till the target size was achieved and colleagues, representatives from the area were approached to get the data. The data were collected between July 2017 and February 2018. Apart from personal data regarding gender, qualification, type of practice, experience, status of conducting CMEs and conferences, professional societies office-bearer status, sponsorship, no of CMEs attended, attendance with or without family, purpose of attending $\mathrm{CME}$ and fulfilment of the purpose all in the last five years was collected. A questionnaire was prepared and was validated by colleagues who conducted, participated regularly in CMEs. The questionnaire is a general and representative type covering various issues related to CME. It consists of eight questions each for general impression about CME (q1- q8) and faculty (f_q1 to f_q8). The opinion regarding CME credit hours for renewal of MCI registration was also obtained by one additional specific question. All the questions had five options in a Likert scale ranging from strongly disagree (1) to strongly agree (5). The data were analysed using Statistical Package for Social Sciences (SPSS Statistical software for Windows version 16.0 Inc., Chicago, USA)) for windows version 16.0 Inc., Chicago, USA). The descriptive statistics were obtained and the Cronbach's alpha was computed for reliability, validity and to know the data adequacy of the test.

\section{RESULTS}

Out of 510 psychiatrists contacted, three informed that they were not in active practice. Five responses were grossly inadequate as they did not answer the questionnaire. A total of 202 responses were found to be adequate and rest did not respond giving a fit for analysis response rate of $39.6 \%$. Out of 202 taken-up for analysis, $136(67 \%)$ were male and 66 (33\%) females. Two-thirds of them were under 40 years, postgraduate degree holders and were in the profession for less than ten years. Also, 17\% were students while $44 \%$ were into purely academic/academic or private practice and $37 \%$ were in pure private practice. Two-fifth conducted CME and nearly a third were officebearers- mostly in city associations. The average number of CMEs attended was 4.4. Most responders attended CMEs alone. Likewise, 36\% were either partly or fully sponsored by pharma companies and $66 \%$ attended because of the topic while $34 \%$ for faculty, $21 \%$ for MCI renewal. More than half were against demand of $\mathrm{CME}$ credit hours for MCI registration renewal.

Both Cronbach's alpha for reliability of the primary data (0.717) and Kaiser-Meyer-Olkin (KMO) test and Bartlett's test of sphericity (KMO test measure of sampling adequacy $=0.734$ and .709 for faculty; approx. Chi-square $=$ 411.70 and 234.228 for faculty; $\mathrm{df}=28$ and Sig. 000 ) indicate fair reliability, sampling adequacy and original variables are sufficiently correlated and reflect on the validity.

The descriptive statistics indicate that general impression about CME through questions 1,2, and 3 and in the faculty through questions 1, 2, 6 and 7. Most of the respondents had a high opinion towards Q1 (I am well satisfied with the programmes), Q2 (the information presented in the programmes was useful in my day to day practice and patient care), Q7 (the programme seems to be more of a business affair than academic) and Q8 (all the points were available in the net and there was nothing new) while Q4 (neither the accrediting authority nor the organizers took the attention span of participants into consideration while planning), Q5 (though the new points learnt appear good academically, in practice they are of not much help) and Q6 (but for the credit points associated with the programmes, I would not have attended them) elicited a medium opinion while Q3 (conducting CME by MCI online will lessen the financial burden to participants) has the least opinion. Similarly, most of the faculty respondents had a high opinion towards Q1 (the quality of the speakers was impressive), Q2 (presented novel concepts), with medium opinion for Q4 (the overall impact of the speakers' presentation leaves much to be desired), Q6 (the faculty provided material clinically relevant that can withstand clinical and statistical scrutiny) and Q7 (the information presented was balanced) 
where as least opiniated for Q3 (originality/expertise seems to be suspect), Q8 (the faculty does not use the concepts projected in their day to day practice) and Q5 (there seems to be a bias and conflict of interest) has least opinion. On the whole, while $58 \%$ participants and $74 \%$ faculty found CME favourably, on the unfavourable side the figure were 21 and $51 \%$ respectively.

\section{DISCUSSION}

This survey is a general opinion of psychiatrists on CMEs of all types including those conducted in the National annual conferences of professional associations which have been attended in the last five years. There might be contradictory opinions about the CME among the participants. However, emphasis was not put on any one issue. The questionnaire aimed to covers all aspects about CME such as cost; alternatives available, perception of the attitude of the speaker, etc.

The response rate of about $40 \%$ is in tune with the observation that psychiatrists respond poorly to surveys. It was less than reported in another survey of Indian psychiatrists. ${ }^{6}$ The lower rate might be due to a reluctance to express negatively on an almost established procedure.

The distribution of psychiatrists as per their age was skewed left which explains the higher preponderance of younger psychiatrists in the responders. The increasing production of psychiatrists started in later nineties and so most of the active psychiatrists are in the younger age group.

One would expect a participant to attend CME for acquiring new knowledge useful for improved patient care and renewal of medical registration. As only 16 states started implementing it, some backtracking, it is not a priority as of now. Further, majority of the psychiatrists are in cities or nearby where getting required CME credit hours is not at all a problem as meetings and CMEs are conducted almost on monthly basis. This is reflected in the survey as only $21 \%$ responders attended for that reason. Further, the antagonism for CME as a condition for renewal gets strengthened by more than half who were not in favour of that move. This leads one to look at CME not from the perspective of credit hours but from its real utility and usefulness to the participants. Unlike in the rest of the world, the biggest and strongest participation in CME growth and development in India happens to come from the pharmaceutical industry. ${ }^{5}$ Several prominent investigations have revealed industry efforts to use educational activities to increase drug sales. ${ }^{7}$ Notwithstanding MCI rule, in the present analysis high pharmacutical industry sponsorship for the participants-either partly or in full at $36 \%$ in comparisons to $1.6 \%$ reported in another study is noteworthy. ${ }^{8}$ Conducting $\mathrm{CME}$ by $\mathrm{MCI}$, for registra- tion purpose if implemented has the advantage of less financial strain as $\mathrm{MCI}$ can use the same set-up for all branches of medicine. Conducting online interacting CME is less of a financial drain. Both have the advantage of less dependence on pharmaceutical companies for funding and acquiring knowledge.

The conduct of CME involves forming like-minded team, deciding on the topic after thorough discussion, selection of speakers, interacting and sorting-out with state $\mathrm{MCI}$, resource mobilization, marketing, and actual conduct of the event. The topic of CME is generally decided by a committee. The topic decided may not be in agreement with the day to day needs of the participants. What the participants want may be a different topic, speaker as evidenced by only $34 \%$ attending for reasons other than topic and $66 \%$ not bothered about faculty. A survey conducted during/at the end of CME may not actually reflect the impact of CME on day to day practice later as the opinion will be biased by ambience, awe of the speaker, complexity bias, lemming effect and other extraneous considerations. In one such exercise where only about $25 \%$ of the delegates completed the feedback forms and gave a feedback on a lecture that was not delivered; some delegates had used the response sheet for taking notes. ${ }^{9}$ Similar observations have been previously reported in other meetings as well..$^{10}$ It was suggested that the CME follow-up period should be at least 12 months to detect the intervention effects and to investigate their sustainability. ${ }^{11}$ Hence, it will be advisable to assess the impact of CME at a later date say many months or a year after and periodically so as to get a dispassionate non orchestrated evaluation of the utility of CME.

Generally, it is the tendency of most of the participants to enquire about the speaker of event they attend. Practicing psychiatrists' get a general idea about the other psychiatrists' way of treatment thru the patients as a good number of chronic patients keep going round different psychiatrists. Further they get information from other colleagues about the way others use for teaching. Many hours of CME in a day does not necessarily lead to absorption of materials presented as evidenced by two-fifths of participants agreeing that the organizers did not take the attention span of participants into consideration while planning. This coupled with the feeling that the speaker does not use the concepts put forward in their practice $(40 \%)$ and a quarter feeling that the material is available on the net leads one to doubt the utility of conventional CME as an educational tool.

There has been a sizable debate and widespread scepticism about the effect of CME. ${ }^{12}$ There was a feeling that all information is available at the click of a button on the internet and busy practitioners feel that it is a waste 
of time and money to attend conferences. ${ }^{13}$ In a broader sense, the present survey is in agreement with that. Further, the standards for CME evaluation are needed to enable comparison among different studies and to detect factors influencing CME evaluation. ${ }^{11}$ More research is needed to determine with any degree of certainty which types of media, techniques, and exposure volumes as well as what internal and external audience characteristics are associated with improvements in outcomes. ${ }^{14}$

Till now, no large scale, systemic study was conducted to study short-term and long-term effect of CME on participants on their day-to-day practice and sustainability of the effect. It is high time that such an exercise is undertaken. One should set priorities and evaluate their achievement of CME. This ideally should be followed by audit by resorting to gathering the opinion of participants, to find out how successful not by the glitter and number registered, but by eliciting impartial and honest opinion of the actual participants, and how much beneficial is it to them and ultimately patients. Following this, the reasons for beneficial or otherwise effect of CME on patient should be probed. In short, cost-benefit analysis and rethink about all aspects of CME is needed. This is needed to avoid the opinion that CME is the conspiracy of the unproductive but organized against the productive but unorganized as the American journalist, Joseph Sobran commented about politics. ${ }^{15}$

The results may be biased due courtesy bias and experimenter effect. The short coming of this survey was not addressing other variables. Any tool for evaluation of a system must be end-user friendly to sustain interest and to get an honest opinion. This survey did not use any professional organization or incentives to respond. Hence, the number of questions was restricted to get maximum responses. The survey and the consequent report, notwithstanding the above, merit consideration as this is the first of its' kind on Indian psychiatrists opinion and the sobering revelation of negative perception of CME of not to be ignored number of psychiatrists.

\section{CONCLUSION}

The cost-benefit analysis and rethink about all aspects of CME is needed.

\section{ACKNOWLEDGMENTS}

Author acknowledge with thanks the help rendered in analysis and suggestions made by Dr Vajjha, Professor,
Birla Institute of Technology and Science, Pilani, Hyderabad and Professor of Statistics (retd.), Osmania University, Hyderabad.

\section{REFERENCES}

1. Accreditation Council of Continuing Medical Education (ACCME-2007). Availablefrom: http:// www.accme.org/tags/ definition-cme? type=faq) accessed on April 12, 2018.

2. CME Programmes MCI India. Available from: https://www. mciindia.org /CMS/ about-mci/cme-programmes.

3. Datta C. The rise of E-learning and opportunities for Indian family physicians. Journal of family medicine and primary care. 2012 Jan;1(1):7-9.

4. Parkar SR, Dawani VS, Apte JS. History of psychiatry in India. Journal of postgraduate Medicine. 2001 Jan 1;47(1):73.

5. Srivastava V, Sullivan L, Sanghvi S. CME/CPD in the Indian Subcontinent: proceedings from the 1st regional meeting of Global Alliance for Medical Education (GAME) in Mumbai, India. Journal of European CME. 2015 Jan 1;4(1):27499.

6. Sarma PG. Burnout in Indian psychiatrists. Indian Journal of Psychological Medicine. 2018 Mar 1;40(2):156-160.

7. Hashmi A, Singh GK. Pharmaceutical industry and continuing medical education. Indian Journal of Dermatology, Venereology, and Leprology. 2010 Sep 1;76(5):581-582.

8. Venkataraman R, Ranganathan L, Ponnish AS, Abraham BK, Ramakrishnan N. Funding sources for continuing medical education: An observational study. Indian journal of critical care medicine: peer-reviewed, official publication of Indian Society of Critical Care Medicine. 2014 Aug;18(8):513-517.

9. Vijayashankar MR. Evaluation of speakers at CME: Cosmecon 2006, an international conference on ageing and anti-ageing. Journal of cutaneous and aesthetic surgery. 2008 Jul;1(2):98-102.

10. Collins J, Mullan BF, Holbert JM. Evaluation of speakers at a national radiology continuing medical education course. Medical education online. 2002 Dec 1;7(1):4540.

11. Tian J, Atkinson NL, Portnoy B, Gold RS. A systematic review of evaluation in formal continuing medical education. Journal of Continuing Education in the Health Professions. 2007 Dec;27(1):16-27.

12. Davis D, Galbraith R. American College of Chest Physicians Health and Science Policy Committee. Continuing medical education effect on practice performance: effectiveness of continuing medical education: American College of Chest Physicians Evidence-Based Educational Guidelines. Chest. 2009 Mar;135(3 Suppl):42S-48S.

13. Sohoni C. Continuing medical education (CME): Why the fuss?. The Indian journal of radiology \& imaging. 2011 Apr;21(2):158.

14. Marinopoulos SS, Dorman T, Ratanawongsa N, Wilson LM, Ashar BH, Magaziner JL, Miller RG, Thomas PA, Prokopowicz GP, Qayyum R, Bass EB. Effectiveness of continuing medical education. Evid Rep Technol Assess (Full Rep). 2007 Jan;149(1):1-69.

15. Top 9 quotes of Joseph Sobran famous quotes, rare quotes and Available from https://www.inspiringquotes.us/author/ 9518-josephsobran. 